\title{
Pilot Randomized Controlled Trial to Reduce Readmission for Heart Failure Using Novel Tablet and Nurse Practitioner Education
}

Running Title: Heart Failure Education

Khadijah Breathett, MD, MS; Scott Maffett, MD; Randi E. Foraker, PhD; Rod Sturdivant, PhD; Kristina Moon, DO; Ayesha Hasan, MD; Veronica Franco, MD; Sakima Smith, MD, MPH; Brent C. Lampert, DO; Sitaramesh Emani, MD; Garrie Haas, MD; Rami Kahwash, MD; Ray E. Hershberger, MD; Philip F. Binkley, MD, MPH; Laura Helmkamp, MS; Kathryn Colborn, PhD; Pamela N. Peterson, MD, MSPH; Nancy Sweitzer, MD, PhD; William T. Abraham, MD

From the Division of Cardiovascular Medicine, Sarver Heart Center, University of Arizona, Tucson, AZ (K.B., N.S.); Division of Cardiovascular Medicine, Ohio State University Wexner Medical Center, Columbus, OH (S.M., A.H., V.F., S.S., B.C.L., S.E., G.H., R.K., R.E.H., P.F.B., W.T.A.); Institute for Informatics, Washington University in St. Louis School of Medicine, St. Louis, MO (R.E.F); Division of Biostatistics, Azusa Pacific University, Azusa, CA (R.S.); Division of Cardiology, University of Wisconsin, Madison, WI (K.M.); University of Colorado Adult and Child Consortium for Health Outcomes Research and Delivery Science, Aurora, CO, United States (L.H., K.C.); Division of Cardiology, University of Colorado and Denver Health Medical Center, Denver, CO (P.N.P.).

All authors had access to data and a role in writing this manuscript.

Dr. Breathett received support from the Ohio State University Department of Medicine seed grant award; National Institute of Health (NIH) L60 MD010857; the University of Colorado, Department of Medicine, Health Services Research Development Grant Award; and the University of Arizona Health Sciences, Strategic Priorities Faculty Initiative Grant. EngineeredCare provided tablets for this study. Tablet applications were developed by EngineeredCare and Dr. Breathett. Dr. Breathett has no 
ownership in EngineeredCare. No employees of EngineeredCare were included with analysis nor development of this manuscript. Otherwise there are no disclosures.

Keywords: heart failure; patient education; nurse practitioner; readmission; educational technology 
Background: Heart failure education programs are not standardized. The best form of education is unclear. We evaluated whether addition of a novel tablet application to nurse practitioner (NP) education was superior to NP education alone in reducing 30-day readmission after heart failure hospitalization.

Methods: From 2/2015-3/2016, patients admitted to a quaternary academic center with primary diagnosis of heart failure were randomized to (1) treatment- NP education plus tablet application (interactive conditional logic program that flags patient questions to medical staff) or (2) control- NP education. The primary outcome was reduction in 30-day readmission rate. Secondary outcomes included satisfaction and education assessed via survey.

Results: Randomization included 60 patients to treatment and 66 to control. A total of 13 patients withdrew prior to intervention (treatment $n=4$, control $n=1$ ) or were lost to follow-up (treatment $n=3$, control $n=5$ ). The 30-day readmission rate trended lower for treatment compared to control, but results were not statistically significant [13.2\% (7/53), $26.7 \%(16 / 60)$, respectively, $p=0.08]$. Similarly, satisfaction trended higher with treatment than control $(p=0.08)$. Treatment patients rated explanations from their physicians higher than control (Always: $83.7 \%, 55.8 \%$, respectively, $p=0.01$ ).

Conclusions: NP education plus tablet use was not associated with significantly lower 30-day readmission rates in comparison to NP alone, but a positive trend was seen. Patient satisfaction trended higher and heart failure explanations were better with NP education plus tablet. A larger study is needed to determine if NP education plus tablet reduces readmission rates following heart failure admission. 


\section{INTRODUCTION}

Readmission rates after heart failure hospitalization remain above goal at over $20 \%$ within 30 days. ${ }^{1}$ Heart failure is one of the leading causes of hospital readmission in the U.S. ${ }^{1}$ Multiple strategies have been taken to reduce 30 -day readmission rates. ${ }^{2,3}$ Heart failure education is perceived as a means of empowering patients to improve outcomes, such as hospital readmission. ${ }^{1}$

The American College of Cardiology Foundation (ACCF) and American Heart Association recommend that heart failure education be provided prior to discharge from the hospital. ${ }^{1}$ Heart failure education has been identified by the ACCF expert consensus as an answer to pivotal issues surrounding care in heart failure patients. ${ }^{4}$ However, the best method of providing heart failure education is unknown, and inpatient heart failure education is not standardized. ${ }^{2}$

Thus, the objective of this pilot study was to determine if nurse practitioner (NP) education and a novel tablet application, which employs individualized conditional logic and flags patient responses to medical staff, is better than NP education alone at reducing 30-day all-cause readmission rates. Secondarily, we hypothesized that satisfaction and education would be improved with addition of the tablet application.

\section{METHODS}

Adult patients admitted with a primary diagnosis of heart failure were eligible for study enrollment. Exclusion criteria included: non-English speakers, observation status, end-stage heart failure, nursing facility residents, vision/hearing impaired, and dementia/delirium.

In this investigator-blinded study, patients were randomized 1:1 to inpatient (1) treatment with NP education plus novel tablet application or (2) control with NP education alone. NP education included one-on-one discussion of heart failure materials outlined in the center's heart failure patient education binder (heart failure overview, medications, lifestyle modification, and triggers for contacting a provider). 
The tablet application was an interactive audio-visual conditional logic program, which provided individualized education and flagged patient questions to medical staff. The application had four specific foci for education: heart failure overview, nutrition plan, importance of medication adherence, and lifestyle modification (Figure).

The primary outcome was 30-day all-cause readmission rate, evaluated by chart review and follow-up phone calls. Secondary outcomes included discharge survey assessments of patient satisfaction and education. Survey questions were modified with permission from 2014 Hospital Consumer Assessment of Healthcare Providers and Systems, and responses used Likert scales.

After 3/31/2016, NP education was no longer available for treatment or control groups. As a secondary analysis, we compared results for (3) treatment with heart failure binder and novel tablet application versus (4) control with heart failure binder. For an effect size of $10 \%, 400$ patients were needed to detect a reduction in readmission rates with a power of 0.8 and alpha of 0.05 . Study enrollment was discontinued prior to reaching target due to scope of funds. Outcomes were compared using chisquared analyses, t-tests, and Mann-Whitney U tests in SAS, version 9.4 (SAS Institute, Inc., Cary, North Carolina). This study obtained Institutional Review Board approval from the Ohio State University.

\section{RESULTS}

From 3/1/2015 - 3/31/2016, 126 patients were enrolled with 60 patients randomized to treatment and 66 to control. Among these patients, 4 treatment and 1 control patients withdrew before active treatment, and 3 treatment and 5 control patients were lost to follow-up. The final analysis included 53 treatment and 60 control patients. 
At baseline, the average age was 60.6 years \pm 13.2 . The majority of patients were men and had heart failure with reduced ejection fraction (Table 1). Baseline characteristics were similar between treatment and control with the exception of diabetes, which was more prevalent in the treatment group.

All-cause readmission rates at 30 days trended lower in patients with treatment compared to control [treatment $13.2 \%(7 / 53)$, control $26.7 \%(16 / 60), p=0.08]$, but was not significant. The survey response rate was $81.1 \%(43 / 53)$ among treatment and $71.7 \%(43 / 60)$ among control patients. Overall patient satisfaction scores trended towards higher satisfaction with treatment than control [treatment median 10.0 (interquartile range 7.5-10.0), control $8.3(6.0-10.0), p=0.08$ (Table 2)]. Patients particularly felt that providers offered better explanations of their care with treatment than control (Always nurses: treatment $86.0 \%$, control $67.4 \%, p=0.04$; Always physicians: treatment $83.7 \%$, control $55.8 \%, p=0.01$ ). Patients perceived better descriptions of medication side effects with treatment than control (Always: treatment $61.1 \%$, control $26.7 \%, p=0.01)$. Trends towards improved understanding of patients' responsibilities and increased likelihood of changing patient plans/behavior were observed with treatment compared to control, but were not significant. Patients' perceptions of readmission likelihood trended lower in treatment versus control, but was not significant. Plans for medication adherence were high in both groups (Definitely yes: treatment 97.6\%, control 100.0\%, $p=0.49$ ).

In the secondary analysis, after NP education was no longer provided (4/1/2016 - 1/31/2017), an additional 34 patients were enrolled, 21 to treatment and 13 to control (withdrawal: treatment $n=2$, control $n=0$; loss to follow-up: treatment $n=4$, control $n=0$ ). Readmission rates trended higher with treatment of heart failure binder and tablet application compared to control of heart failure binder alone [60.0\% (9/15) heart failure binder and tablet application, 38.5\% (5/13) heart failure binder, $p=0.26]$. Overall 30-day readmission rates without NP education $(50.0 \%, 14 / 28)$ were higher than rates with NP education $(20.4 \%, 23 / 113)(p=0.001)$. 


\section{DISCUSSION}

Compared to NP education alone, the combination of NP education and a conditional logic-based tablet application demonstrated trends towards reduction in 30-day all-cause readmission and improved patient satisfaction. The trend reversed when NP education was not provided to either group. This pilot study suggests that one-on-one heart failure education may reduce readmission rates after initial heart failure hospitalization, and the addition of novel tablet application may further reduce readmission rates.

Similar to this study, heart failure patient education has been effective at improving multiple outcomes. ${ }^{1,5}$ In a systematic review of 35 heart failure education studies, the majority demonstrated reduction in readmission after heart failure hospitalization and improvements in patient understanding of heart failure. ${ }^{5}$ Patient satisfaction was equivocal. ${ }^{5}$ However, as observed in registry data, ${ }^{2}$ the format of heart failure education were highly variable, ranging from print handouts to audio/visual presentations. $^{5}$

Rapid advances in technology have contributed to an abundance of computer applications designed to improve heart failure outcomes. ${ }^{6}$ Our results are supported by a recent meta-analysis which demonstrated reduced risk of heart failure hospitalizations with the usage of computer applications compared to education that excludes computer applications. ${ }^{6}$ Key components of these applications included personalized heart failure education, ability to communicate with health care providers, and telemonitoring. ${ }^{6}$ Compared to our study, these trials were missing results for the combination of one-onone education and computer application. ${ }^{6}$

One-on-one heart failure education may be the appropriate standard of care upon which to expand heart failure education with computer technology. Although heart failure education methods are variable, ${ }^{2}$ a unifying method was found in the systematic review of heart failure education, one-on-one patient education. ${ }^{5}$ In the review, educators' backgrounds varied from health care providers to trained lay persons. ${ }^{5}$ Similarly, an hour of inpatient heart failure education by a registered nurse was successful 
in reducing readmissions. ${ }^{5}$ One-on-one heart failure education allows for direct patient communication, and computer applications provide opportunity for patient self-directed care and learning. The combination of one-on-one heart failure education with computer applications has the potential to further reduce readmission rates.

This study is subject to several limitations. First, it was underpowered. This was a single-center pilot study. The intervention will need evaluation in multiple centers to confirm positive trends and enhance external validity. Second, the latter end of the study had no NP education, and the intervention arm of tablet education combined with heart failure binder trended towards worse results than heart failure binder alone. This highlights the importance of one-on-one education with an NP.

\section{CONCLUSIONS}

Compared to NP education alone, NP education plus tablet application did not significantly reduce 30 day readmission rates, but did demonstrate a trend towards reduced readmissions and improved satisfaction. Education was improved with this combination. The absence of NP education resulted in higher readmission rates. These findings support the need for a larger multi-center study that compares provider-based education to the combination of one-on-one education and tablet application. 


\section{REFERENCES}

1. Yancy CW, Jessup M, Bozkurt B, et al. 2013 ACCF/AHA Guideline for the Management of Heart Failure A Report of the American College of Cardiology Foundation/American Heart Association Task Force on Practice Guidelines. Circulation. June 2013:CIR.0b013e31829e8776. doi:10.1161/CIR.0b013e31829e8776

2. Kociol RD, Peterson ED, Hammill BG, et al. National survey of hospital strategies to reduce heart failure readmissions: findings from the Get With the Guidelines-Heart Failure registry. Circ Heart Fail. 2012;5(6):680-687. doi:10.1161/CIRCHEARTFAILURE.112.967406

3. Breathett K, D'Amico R, Adesanya TMA, et al. Patient Perceptions on Facilitating Follow-Up After Heart Failure Hospitalization. Circ Heart Fail. 2017;10(6).

doi:10.1161/CIRCHEARTFAILURE.117.004099

4. Committee HFPW, Yancy CW, Januzzi JL, et al. 2017 ACC Expert Consensus Decision Pathway for Optimization of Heart Failure Treatment: Answers to 10 Pivotal Issues About Heart Failure With Reduced Ejection Fraction. J Am Coll Cardiol. December 2017:24465.

doi:10.1016/j.jacc.2017.11.025

5. Boren SA, Wakefield BJ, Gunlock TL, Wakefield DS. Heart failure self-management education: a systematic review of the evidence. Int J Evid Based Healthc. 2009;7(3):159-168. doi:10.1111/j.1744-1609.2009.00134.x

6. Or CK, Tao D, Wang $\mathrm{H}$. The effectiveness of the use of consumer health information technology in patients with heart failure: A meta-analysis and narrative review of randomized controlled trials. $J$ Telemed Telecare. 2017;23(1):155-166. doi:10.1177/1357633X15625540 


\section{FIGURE LEGEND}

Figure. Tablet Application Screenshot Addressing Medication Adherence. 


\section{CLINICAL SIGNIFICANCE}

- Heart failure education is not standardized, and clinical support for patient education is variable across hospital centers.

- The combination of novel tablet education and one-on-one nurse practitioner education may reduce hospital readmission rates and improve patient satisfaction and education. 
TABLES

Table 1. Baseline Characteristics

\begin{tabular}{|c|c|c|c|}
\hline & $\begin{array}{l}\text { Treatment } \\
\mathrm{N}=53\end{array}$ & $\begin{array}{l}\text { Control } \\
\mathrm{N}=60\end{array}$ & $\begin{array}{l}p- \\
\text { value }\end{array}$ \\
\hline Men & $73.6 \%$ & $63.3 \%$ & 0.24 \\
\hline Age, mean $\pm S D$ & $61.1 \pm 12.8$ & $60.2 \pm 13.6$ & 0.72 \\
\hline $\begin{array}{l}\text { Race } \\
\text { African-American } \\
\text { Caucasian } \\
\text { Other }\end{array}$ & $\begin{array}{l}20.8 \% \\
52.8 \% \\
26.4 \%\end{array}$ & $\begin{array}{l}20.0 \% \\
48.3 \% \\
31.7 \%\end{array}$ & 0.82 \\
\hline LVEF, mean \pm SD & $35 \% \pm 18$ & $34 \% \pm 16$ & 0.90 \\
\hline $\begin{array}{l}\text { Comorbidities } \\
\text { Anemia } \\
\text { Atherosclerosis } \\
\text { Atrial fibrillation/flutter } \\
\text { Cerebral vascular accident } \\
\text { Chronic kidney disease } \\
\text { Chronic obstructive pulmonary disease } \\
\text { Depression } \\
\text { Diabetes mellitus } \\
\text { End stage renal disease } \\
\text { Hyperlipidemia } \\
\text { Hypertension } \\
\text { Obesity } \\
\text { Peripheral Vascular Disease } \\
\text { Tobacco ongoing }\end{array}$ & $\begin{array}{r}48.1 \% \\
25.0 \% \\
44.2 \% \\
5.8 \% \\
32.7 \% \\
23.1 \% \\
19.2 \% \\
67.3 \% \\
1.9 \% \\
55.8 \% \\
78.4 \% \\
57.7 \% \\
7.7 \% \\
7.7 \%\end{array}$ & $\begin{array}{r}37.9 \% \\
18.3 \% \\
43.3 \% \\
5.0 \% \\
43.3 \% \\
30.0 \% \\
28.3 \% \\
45.0 \% \\
0.0 \% \\
56.7 \% \\
83.3 \% \\
51.7 \% \\
1.7 \% \\
18.6 \%\end{array}$ & $\begin{array}{l}0.28 \\
0.39 \\
0.92 \\
>0.99 \\
0.25 \\
0.41 \\
0.26 \\
0.02 \\
0.47 \\
0.92 \\
0.51 \\
0.52 \\
0.18 \\
0.22\end{array}$ \\
\hline $\begin{array}{l}\text { Insurance } \\
\text { Marketplace } \\
\text { Medicare/Medicaid } \\
\text { Private } \\
\text { Self-pay }\end{array}$ & $\begin{array}{c}28.0 \% \\
66.0 \% \\
4.0 \% \\
2.0 \%\end{array}$ & $\begin{array}{l}35.0 \% \\
58.3 \% \\
3.3 \% \\
3.3 \%\end{array}$ & 0.85 \\
\hline $\begin{array}{l}\text { Education } \\
\text { Less than high school } \\
\text { High school } \\
\text { College }\end{array}$ & $\begin{array}{c}9.8 \% \\
34.1 \% \\
56.1 \%\end{array}$ & $\begin{array}{l}16.7 \% \\
31.0 \% \\
52.4 \%\end{array}$ & 0.79 \\
\hline $\begin{array}{c}\text { Annual Income } \\
<\$ 10,000 \\
\$ 10-34,999 \\
\$ 35-59,999 \\
\geq \$ 60,000\end{array}$ & $\begin{array}{l}26.3 \% \\
28.9 \% \\
18.4 \% \\
26.3 \%\end{array}$ & $\begin{array}{l}13.2 \% \\
42.1 \% \\
15.8 \% \\
28.9 \%\end{array}$ & 0.44 \\
\hline
\end{tabular}

SD indicates standard deviation. 
Table 2. Patient Survey Results

\begin{tabular}{|c|c|c|c|}
\hline & $\begin{array}{l}\text { Treatment } \\
\mathrm{N}=43\end{array}$ & $\begin{array}{l}\text { Control } \\
\mathrm{N}=43\end{array}$ & p-value \\
\hline Overall Patient Satisfaction Score, median (IQR) & $\begin{array}{l}10.0 \\
(7.5-10.0)\end{array}$ & $\begin{array}{l}8.3 \\
(6.0-10.0)\end{array}$ & 0.08 \\
\hline \multicolumn{4}{|l|}{ Patient Satisfaction } \\
\hline $\begin{array}{l}\text { Nurses: Treat patient with respect } \\
\text { Listen to patients } \\
\text { Provide good explanations }\end{array}$ & $\begin{array}{l}93.0 \% \\
76.7 \% \\
86.0 \%\end{array}$ & $\begin{array}{l}93.0 \% \\
74.4 \% \\
67.4 \%\end{array}$ & $\begin{array}{l}>0.99 \\
0.80 \\
0.04^{*}\end{array}$ \\
\hline $\begin{array}{l}\text { Doctors: Treat patients with respect } \\
\text { Listen to patients } \\
\text { Provide good explanations }\end{array}$ & $\begin{array}{l}95.3 \% \\
86.0 \% \\
83.7 \%\end{array}$ & $\begin{array}{l}88.4 \% \\
72.1 \% \\
55.8 \%\end{array}$ & $\begin{array}{l}0.43 \\
0.11 \\
0.01^{*}\end{array}$ \\
\hline $\begin{array}{l}\text { New Medications: Anything new } \\
\text { Provide reason before giving } \\
\text { Described side effects before giving }\end{array}$ & $\begin{array}{l}78.6 \% \\
86.1 \% \\
61.1 \%\end{array}$ & $\begin{array}{l}55.8 \% \\
75.9 \% \\
26.7 \%\end{array}$ & $\begin{array}{l}0.03^{*} \\
0.29 \\
0.01^{*}\end{array}$ \\
\hline $\begin{array}{l}\text { Discuss adequacy of help needed before discharge } \\
\text { Symptoms to look for upon discharge were written } \\
\text { Would recommend this hospital to others } \\
\text { Staff considered patient preferences when } \\
\text { determining pre-discharge needs }\end{array}$ & $\begin{array}{l}95.2 \% \\
95.1 \% \\
93.0 \% \\
64.3 \%\end{array}$ & $\begin{array}{l}87.5 \% \\
81.6 \% \\
85.7 \% \\
57.5 \%\end{array}$ & $\begin{array}{l}0.26 \\
0.08 \\
0.31 \\
0.53\end{array}$ \\
\hline $\begin{array}{l}\text { Patient Understanding } \\
\text { Responsibility in managing health } \\
\text { Purpose of heart medications } \\
\text { Meaning of heart failure } \\
\text { When to call regarding symptom worsening } \\
\text { Type of foods to eat } \\
\text { Know patient weight }\end{array}$ & $\begin{array}{l}82.9 \% \\
83.3 \% \\
78.6 \% \\
76.2 \% \\
71.4 \% \\
67.5 \%\end{array}$ & $\begin{array}{l}68.3 \% \\
80.0 \% \\
70.0 \% \\
70.0 \% \\
70.0 \% \\
56.4 \%\end{array}$ & $\begin{array}{l}0.12 \\
0.70 \\
0.37 \\
0.53 \\
0.89 \\
0.31\end{array}$ \\
\hline \multicolumn{4}{|l|}{ Patient Beliefs } \\
\hline $\begin{array}{l}\text { Patient Plans } \\
\text { Weigh self daily } \\
\text { Take medications regularly } \\
\text { Consume less than } 2 \text { grams of sodium daily } \\
\text { Exercise three times or more per week }\end{array}$ & $\begin{array}{l}78.6 \% \\
97.6 \% \\
83.3 \% \\
69.0 \%\end{array}$ & $\begin{array}{l}72.1 \% \\
100.0 \% \\
79.1 \% \\
68.3 \%\end{array}$ & $\begin{array}{l}0.49 \\
0.49 \\
0.62 \\
0.94\end{array}$ \\
\hline
\end{tabular}

Modified HCAPHS survey with permission. Higher score indicates increased satisfaction; IQR, interquartile range; *, $p$ value $<0.05$. Other satisfaction questions are demonstrated as percentages for always, patient understanding and belief questions are demonstrated as highest values on Likert scale combining strongly agree and agree, and patient plans are demonstrated for highest value on Likert scale. 


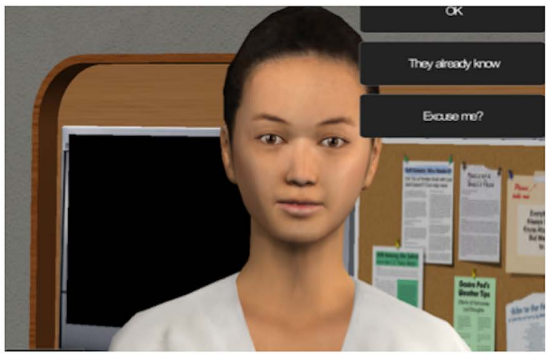

Focus:

1. Understanding Heart Failure

2. Nutrition Plan

3. Importance of taking medications

4. Lifestyle/Activities

This provides an example of the patient being asked about problems with taking medications. This question gauges whether or not the patient has shared difficulties with his/her healthcare providers. Patients may respond audibly or electronically. 